\title{
An EGFR Targeted PET Imaging Probe for the Detection of Colonic Adenocarcinomas in the Setting of Colitis
}

\author{
N. Selcan Turker ${ }^{1}$, Pedram Heidari ${ }^{1}$, Raju Kucherlapati ${ }^{2}$, Melanie Kucherlapati², Umar Mahmood ${ }^{1}{ }^{凶}$ \\ 1. Athinoula A. Martinos Center for Biomedical Imaging, Department of Radiology, Massachusetts General Hospital, Harvard Medical \\ School, Boston, MA; \\ 2. Department of Medicine/Division of Genetics, Brigham and Women's Hospital, Harvard Medical School, Boston, MA.
}

\begin{abstract}
$\triangle$ Corresponding author: Umar Mahmood, MD. PhD. Athinoula A. Martinos Center for Biomedical Imaging, Department of Radiology, Massachusetts General Hospital, Boston, MA. Tel: 617-726-6477 Email: umahmood@mgh.harvard.edu.

() Ivyspring International Publisher. This is an open-access article distributed under the terms of the Creative Commons License (http://creativecommons.org/ licenses/by-nc-nd/3.0/). Reproduction is permitted for personal, noncommercial use, provided that the article is in whole, unmodified, and properly cited.
\end{abstract}

Received: 2014.04.I7; Accepted: 2014.06.04; Published: 2014.07.0I

\begin{abstract}
Colorectal cancer is a serious complication associated with inflammatory bowel disease, often indistinguishable by screening with conventional FDG PET probes. We have developed an alternative EGFR-targeted PET imaging probe that may be used to overcome this difficulty, and successfully assessed its utility for neoplastic lesion detection in preclinical models. Cetuximab $F\left(a b^{\prime}\right) 2$ fragments were enzymatically generated, purified, and DOTA-conjugated. Radiolabeling was performed with ${ }^{67} \mathrm{Ga}$ for cell based studies and ${ }^{64} \mathrm{Cu}$ for in vivo imaging. Competitive binding studies were performed on CT26 cells to assess affinity $\left(K_{D}\right)$ and receptors per cell $\left(B_{\max }\right)$. In vivo imaging using the EGFR targeted PET probe and ${ }^{18} \mathrm{~F} \mathrm{FDG}$ was performed on CT26 tumor bearing mice in both control and dextran sodium sulfate (DSS) induced colitis settings. Spontaneous adenomas in genetically engineered mouse (GEM) models of colon cancer were additionally imaged. The EGFR imaging agent was generated with high purity (>98\%), with a labeling efficiency of $60 \pm 5 \%$ and $\geq 99 \%$ radiochemical purity. The $K_{D}$ was $6.6 \pm 0.7 \mathrm{nM}$ and the $B_{\max }$ for CT26 cells was $3.3 \pm 0.1 \times 10^{6}$ receptors/cell. Target to background ratios (TBR) for CT26 tumors compared to colonic uptake demonstrated high values for both ${ }^{18} \mathrm{~F}$-FDG $(3.95 \pm 0.13)$ and the developed ${ }^{64} \mathrm{Cu}$-DOTA-cetuximab-F(ab') 2 probe $(4.42 \pm 0.1 \mathrm{I})$ in control mice. The TBR for the EGFR targeted probe remained high $(3.78 \pm 0.06)$ in the setting of colitis, while for ${ }^{18} \mathrm{~F} \mathrm{FDG}$, this was markedly reduced $(1.54 \pm 0.08)$. Assessment of the EGFR targeted probe in the GEM models demonstrated a correlation between radiotracer uptake in spontaneous colonic lesions and the EGFR staining level ex vivo. A clinically translatable PET imaging probe was successfully developed to assess EGFR. The imaging agent can detect colonic tumors with a high TBR for detection of in situ lesions in the setting of colitis, and opens the possibility for a new approach for screening high-risk patients.
\end{abstract}

Key words: Positron emission tomography (PET) imaging, molecular imaging, EGFR, ulcerative colitis, colorectal cancer, mouse models.

\section{Introduction}

Inflammatory bowel disease (IBD), which consists of Crohn's disease (CD) and ulcerative colitis (UC), is a chronic inflammatory condition that results from dysregulation of the mucosal immune system in the gastrointestinal tract $t^{1}$. The incidence of IBD is increasing, and 1.4 million people in the United States and 2.2 million people in Europe are affected by the disease $^{2}$. Colorectal cancer (CRC) is one of the most serious complications of IBD involving the colon, and is responsible for $10-15 \%$ of IBD deaths. CRC is curable at the early stages and early detection of CRC or colonic adenomas resulting from chronic inflamma- 
tion is a major focus of current research studies to improve patient survival ${ }^{3}$. Endoscopic guided biopsy is the standard for the diagnosis of CRC and periodic colonoscopy examinations reduces the mortality risk in IBD-associated $\mathrm{CRC}^{4}$. However, the issues surrounding endoscopic screening are exacerbated in ulcerative colitis (UC), in which dysplasia can develop in macroscopically normal-appearing mucosa ${ }^{5}$. Current colonoscopic surveillance in UC patients relies on random biopsies throughout the colon, which is a relatively insensitive and cumbersome strategy that is not widely utilized ${ }^{6}$. Because periodic screening is essential to reduce the incidence of IBD-associated $\mathrm{CRC}$, the development of better molecular imaging technologies to detect CRC in the setting of colitis could provide a new approach for screening in this setting.

Positron emission tomography (PET) is of considerable importance to clinicians in the staging and treatment planning in patients with $\mathrm{CRC}^{7}$. ${ }^{18}$ F-Fluorodeoxyglucose (FDG) is a glucose analog that is the most widely employed PET radioligand in oncology, given the increased glycolysis rate often observed in tumors. However, inflammatory cells are also glycolytically active ${ }^{8}$, and ${ }^{18}$ F FDG has been used to monitor the degree of active inflammation in IBD $^{8-10}$. Improved differentiation between neoplastic and nonneoplastic lesions is important in target selection for molecular imaging ${ }^{11}$. Detection of the increased glycolytic activity of CRC in the setting of increased glycolytic activity seen in IBD may result in a poor target to background ratio (TBR) for ${ }^{18} \mathrm{~F}-\mathrm{FDG}$.

We hypothesized that highly expressed epitopes on CRC tumor cells may provide an alternative target for imaging in this setting. We noted that epidermal growth factor receptor (EGFR) overexpression is present in approximately $80 \%$ of CRC cases, correlated with poor prognosis, decreased survival, and early recurrence ${ }^{12}$. While EGFR overexpression by itself does not directly result in utility as a therapeutic target, based in part on downstream K-RAS and additional signaling requirements ${ }^{13}$, the high rate of overexpression may be exploited as a target for lesion detection $^{14}$. Inflammatory cell lineages do not overexpress EGFR, and thus in the setting of colitis, imaging based on EGFR expression may result in high TBR for detection of in situ cancer ${ }^{15}$. We developed a novel EGFR targeted PET imaging agent and tested the probe to assess radioligand uptake in colon cancer allografts, spontaneous colonic adenomas in genetically engineered mouse models, and in chemically induced colitis. We compared the TBR for allografts and colitis for the EGFR targeted probe relative to ${ }^{18}$ F-FDG.

\section{Materials and Methods \\ Preparation of $F\left(a b^{\prime}\right) 2$ fragments}

Cetuximab $\mathrm{F}\left(\mathrm{ab} \mathrm{b}^{\prime}\right) 2$ fragments were prepared by specific enzymatic digestion using a FragIT ${ }^{\text {TM }}$ MicroSpin column (Genovis, Lund, Sweden) and the crude digest was purified by an immobilized $\mathrm{NAb}^{\mathrm{TM}}$ Protein A spin column (ThermoScientific Sci, Rockford, IL, USA) to remove the Fc fragment. The purity of cetuximab-F( $\left(\mathrm{ab}^{\prime}\right) 2$ was assessed with sodium dodecyl sulfate polyacrylamide gel electrophoresis (SDSPAGE) on a $4-15 \%$ Mimi-PROTEAN ${ }^{\circledR}$ TGX mini-gel (Bio-Rad, Mississauga, ON, Canada) and with fast protein liquid chromatography (FPLC). $\mathrm{F}(\mathrm{ab}) 2$ was electrophoresed under non-reducing conditions with SDS-PAGE and the gel was stained with Bio-Safe ${ }^{\mathrm{TM}}$ Coomassie G-250 stain (Bio-Rad, Mississauga, ON, Canada). FPLC was performed on a HIPREP'M 26/60 Sephacryl ${ }^{\mathrm{TM}}$ S-200 HR column (GE Healthcare Bio-Sciences $\mathrm{AB}$, Björkgatan, Uppsala, Sweden) and eluted with $100 \mathrm{mM} \mathrm{NaH} \mathrm{PO}_{4}$ buffer ( $\mathrm{pH} \mathrm{7.0)}$ at a flow rate of $1.2 \mathrm{~mL} / \mathrm{min}$ at $280 \mathrm{~nm}$. Trace metals were removed from all buffers using Chelex ${ }^{\circledR}-100$ cation-exchange resin (Sigma-Aldrich, Saint Louis, MO, USA). Cetuximab-F( $\left(a b^{\prime}\right) 2$ fragments were concentrated and buffer-exchanged into 0.1 M HEPES buffer, $\mathrm{pH} 8.9$ on an Amicon Ultracel $30 \mathrm{~K}$ device $(\mathrm{MWCO}=$ $30 \mathrm{kDa}$; EMD Millipore Corporation, Billerica, MA, USA $)^{16}$. Cetuximab-F(ab') 2 was conjugated with the bifunctional 2-(4-isothiocyanatobenzyl)-1,4,7,10tetraazacyclodo-decane-1,4,7,10-tetraacetic acid (p-SCN-Bn-DOTA, Macrocyclics, Inc., Dallas, TX, USA) chelate in anhydrous DMSO by a modification of established methods using 10 fold molar excess of chelate to cetuximab $\mathrm{F}\left(\mathrm{ab} \mathrm{b}^{\prime}\right) 2^{17}{ }^{18}$. Conjugation was allowed to proceed overnight at $2-8{ }^{\circ} \mathrm{C}$. DOTA-cetuximab- $\mathrm{F}\left(\mathrm{ab}^{\prime}\right) 2$ was purified from excess DOTA by the Amicon Ultracel $30 \mathrm{~K}$ device with 0.25 $\mathrm{M}$ ammonium acetate buffer ( $\mathrm{pH}$ 6.0) and centrifuging at $3500 \mathrm{rpm}$ for $10 \mathrm{~min}$. This purification step was repeated six times. Finally, purified DOTAcetuximab- $\mathrm{F}\left(\mathrm{ab}^{\prime}\right) 2$ was recovered and the concentration determined spectrophotometrically $[\mathrm{E} 280 \mathrm{~nm}=$ $1.45(\mathrm{mg} / \mathrm{mL})-1 \mathrm{~cm}-1]^{19}$. The final concentration was adjusted with $0.25 \mathrm{M}$ ammonium acetate buffer $(\mathrm{pH}$ 6.0) for aliquoting.

The DOTA substitution level of the $F\left(a b^{\prime}\right) 2$ fragments (chelators/molecule) was measured by labeling a $10 \mu \mathrm{L}$ aliquot of the unpurified conjugate with ${ }^{67} \mathrm{Ga}$ and then determining the proportion of ${ }^{67} \mathrm{Ga}$-DOTA-cetuximab-F(ab') 2 vs. free ${ }^{67} \mathrm{Ga}$-DOTA by ITLC-SG and multiplying this fraction by the molar ratio used in the reaction ${ }^{19}$. 


\section{Radiolabeling procedures}

Radiolabeling was done with ${ }^{67} \mathrm{Ga}$ (MDSNordion, Kanata, Canada) or ${ }^{64} \mathrm{Cu}$ (University of Wisconsin, Madison, WI) as described previously ${ }^{20,21}$. We used ${ }^{67} \mathrm{Ga}$ for cell binding assays due to its relatively longer half-life ( $3.26 \mathrm{~d}$ ) in comparison with ${ }^{64} \mathrm{Cu}$ $(0.529 \mathrm{~d})$ and lower energy, facilitating the cell study workflow. Briefly the ${ }^{67} \mathrm{Ga}$ radioisotope $(1-5 \mathrm{mCi})$ was added to the conjugate $(50-100 \mu \mathrm{g})$ dissolved in 10 $\mathrm{mM}$ sodium acetate buffer ( $\mathrm{pH} 4.5$ ) and then incubated at $40^{\circ} \mathrm{C}$ for $90 \mathrm{~min} .{ }^{64} \mathrm{Cu}$ radiolabeling was performed by incubating 50-100 $\mu \mathrm{g}$ of DOTA-cetuximab$\mathrm{F}\left(\mathrm{ab}^{\prime}\right) 2$ in $0.25 \mathrm{M}$ ammonium acetate buffer ( $\mathrm{pH}$ 6.0) with ${ }^{64} \mathrm{CuCl}_{2}$ for $90 \mathrm{~min}$ at $40^{\circ} \mathrm{C}$ with constant shaking. The ${ }^{67} \mathrm{Ga} /{ }^{64} \mathrm{Cu}$-radiolabeled compounds were purified from free ${ }^{67} \mathrm{Ga} /{ }^{64} \mathrm{Cu}$ and other low molecular weight impurities on an Amicon Ultracel $30 \mathrm{~K}$ device. The purity of the labeled compounds were checked by size exclusion chromatography using a PD-10 Desalting Column (GE Healthcare Bio-Sciences AB, Björkgatan, Uppsala, Sweden) eluting with phosphate-buffered saline (PBS) as the mobile phase. The two different isotopes were used for in vivo and in vitro studies, in order to more closely match the isotope half-lives with the differences in length of the respective studies.

\section{Cell culture}

CT26 murine colorectal carcinoma and HCT-116 human colorectal carcinoma were obtained from the American Type Culture Collection (ATCC). They were cultured in RPMI and McCoy's 5a Medium (ATCC) and supplemented with $10 \%(\mathrm{v} / \mathrm{v})$ fetal bovine serum (FBS), $100 \mathrm{U} / \mathrm{mL}$ penicillin, and 100 $\mu \mathrm{g} / \mathrm{mL}$ streptomycin respectively. The cells were maintained in a humidified atmosphere of $5 \% \mathrm{CO}_{2}$ at $37^{\circ} \mathrm{C}$.

\section{Competitive binding studies}

The EGFR binding affinity of ${ }^{67} \mathrm{Ga}$-DOTAcetuximab- $\mathrm{F}\left(\mathrm{ab}^{\prime}\right) 2$ was determined by direct (saturation) radioligand binding assays in triplicate using a fixed concentration of cetuximab and increasing concentration of ${ }^{67} \mathrm{Ga}-\mathrm{DOTA}$-cetuximab-F( $\left(\mathrm{ab}^{\prime}\right) 2$ on the CT26 cell line with slight modification of previous studies $^{22}$. Briefly, increasing concentrations (0 to 100 $\mathrm{nmol} / \mathrm{L})$ of ${ }^{67} \mathrm{Ga}-\mathrm{DOTA}-\mathrm{cetuximab}-\mathrm{F}\left(\mathrm{ab}^{\prime}\right) 2$ was incubated with $1 \times 10^{5}$ cells in 24 -well plates at $4^{\circ} \mathrm{C}$ for 3 hr. Unbound radioactivity was removed and the dishes were rinsed three times with ice cold PBS and cells detached with $0.05 \%$ trypsin. The number of cells in each well was counted using an automated cell counter (Countess ${ }^{\circledR}$, Invtrogen, NY, USA) and the total cell-bound radioactivity (TB) was measured in a gamma counter (Wizard 2480, Perkin Elmer, MA,
USA). The assay was repeated in the presence of 16 $\mu \mathrm{mol} / \mathrm{L}$ of unlabeled cetuximab to measure non-specific binding (NSB) at $4^{\circ} \mathrm{C}$ for $2 \mathrm{~h}$. Specific binding (SB) was calculated by subtracting NSB from $\mathrm{TB}$ and was plotted vs. the concentration of ${ }^{67} \mathrm{Ga}$-DOTA-cetuximab-F( $\left(\mathrm{ab}^{\prime}\right) 2$ added. The resulting curve was fitted by non-linear regression to a one-site receptor-binding model by Prism software (GraphPad, San Diego, CA, USA). The dissociation constant $\left(K_{D}\right)$ and maximum number of receptors per cell (Bmax) was calculated.

\section{Western Blot Analysis}

In order to ensure EGFR expression in CT26 and HCT-116 cells, Western blot analysis was carried out as previously described ${ }^{23}$. EGFR expression level of CT26 was compared with the high EGFR expressing HCT116 human colon cancer cell line. Briefly, EGFR and beta-actin were detected with EGFR receptor XP rabbit $\mathrm{mAb}$ (Cell Signaling, Danvers, MA, USA) (1:1000 dilution) and beta-actin rabbit $\mathrm{mAb}$ (Cell Signaling, Danvers, MA, USA) (1:1000 dilution). Then the proteins were incubated with goat anti-rabbit IgG-HRP (Santa Cruz Biotechnology, Inc., Santa Cruz, CA, USA) and detected using the BM chemiluminescence Western blotting kit (Roche Diagnostics, Indianapolis, IN, USA) and bands were visualized with a Kodak in vivo FX PRO system (Carestream Health, New Haven, CT, USA).

\section{Animal models}

All animal experiments were approved by our Institutional Animal Care Committee. Mice were maintained with free access to standard chow and water. Female BALB/c mice ( 6 weeks old, with a body weight of 18-20 g) were purchased from Charles River Laboratories International Inc. Dextran Sulfate Sodium (DSS)-treated mice were prepared by the administration of $3.0 \%$ DSS (mol wt 40,000-50,000, MP Affymetrix, Inc., Cleveland, Ohio, USA.) in drinking water for seven days, followed by a regimen of three days of normal drinking water, as described previously $^{24}$. Control mice received water ad libitum. Fresh DSS solutions were prepared daily and mice were recorded daily for the body weight loss, which was calculated relative to day 0 . Subcutaneous (s.c) CT26 tumors were established in a subset of BALB/C mice by s.c injection of $100 \mu \mathrm{L}$ (10 cells) of CT26 cell suspension in Matrigel (BD Biosciences, Franklin Lakes, NJ, USA) in the right upper flank.

To further assess the imaging method, mice with conditional knockout (CKO) mutant alleles were generated as previously described $25,26,27,28$ and $A p c^{C K O} p 53^{\text {floxflo }}$ and Apc LoxP/ LoxPMsh2null/LoxP mutant mouse models were used to evaluate the imaging 
potential of ${ }^{64} \mathrm{Cu}$-DOTA-cetuximab-F(ab')2 in CRC.

\section{PET/CT imaging protocol}

Before imaging with ${ }^{18} \mathrm{~F}-\mathrm{FDG}$, the mice were kept fasted for $4 \mathrm{hr}$ and allowed free access to water. For PET/CT imaging, approximately $400 \mu \mathrm{Ci}$ of ${ }^{18} \mathrm{~F}-\mathrm{FDG}$ or $100 \mu \mathrm{Ci}$ of ${ }^{64} \mathrm{Cu}$-DOTA-cetuximab-F(ab') 2 in a final volume of $200 \mu \mathrm{l}$ was injected to each mouse via the tail vein under $2 \%$ isoflurane gas anesthesia.

PET data were acquired using a whole-body emission protocol on an Argus small-animal PET/CT scanner (Sedecal, Madrid, Spain) for $15 \mathrm{~min}$ in 2 bed positions $1 \mathrm{hr}$ after ${ }^{18} \mathrm{~F}-\mathrm{FDG}$ and $24 \mathrm{hr}$ after ${ }^{64} \mathrm{Cu}$-DOTA-cetuximab-F( $\left(\mathrm{ab}^{\prime}\right) 2$ injection under gas anesthesia with $1.5 \%$ isoflurane. Images were reconstructed with a 2D ordered-subset expectation maximization (2D-OSEM) algorithm (2 iterations, 16 subsets, with scatter and randoms corrections). CT data were acquired in standard resolution. The scan parameters were set as follow: tube voltage $40 \mathrm{kVp}$, tube current $140 \mu \mathrm{A}$, number of projections 360 , number of shots 8 , axial field-of-view $80 \mathrm{~mm}$. Scans were recorded without respiratory gating. Total scan duration was approximately $14 \mathrm{~min}$. Image data were reconstructed using FeldKemp algorithm. Three-dimensional regions of interest (ROI) were manually drawn around tumors based on co-registered CT scans acquired immediately after PET imaging. Mean standardized uptake values (SUVs) were calculated within the ROI.

\section{Antibody blocking studies}

Blocking studies were carried out to evaluate EGFR specificity of ${ }^{64} \mathrm{Cu}$-DOTA-cetuximab-F $\left(\mathrm{ab}^{\prime}\right) 2$ in vivo. Mice bearing CT26 allografts $(\mathrm{n}=4)$ were each intravenously injected with $1.5 \mathrm{mg}$ of cetuximab $24 \mathrm{hr}$ before ${ }^{64} \mathrm{Cu}$-DOTA-cetuximab-F $\left(\mathrm{ab}^{\prime}\right) 2$ administration. The control group mice with CT26 allografts $(n=4)$ were injected with intravenous PBS $24 \mathrm{hr}$ before ${ }^{64} \mathrm{Cu}$-DOTA-cetuximab-F( $\left(\mathrm{ab}^{\prime}\right) 2$ injection. ${ }^{64} \mathrm{Cu}$-DOTAcetuximab- $\mathrm{F}\left(\mathrm{ab}^{\prime}\right) 2$ was intravenously injected into each mouse under isoflurane anesthesia and static PET/CT scans were acquired at $24 \mathrm{hr}$ post injection. Mean standardized uptake values (SUVs) of the allografts were calculated and compared between groups.

\section{PET/CT imaging with ${ }^{18}$ F-FDG and ${ }^{64} \mathrm{Cu}-$ DOTA-cetuximab-F(ab')2}

PET was performed to quantitate the effect of intestinal inflammation upon bowel ${ }^{18}$ F-FDG uptake, as measured in BALB/c mice induced with DSS. ${ }^{18} \mathrm{~F}-\mathrm{FDG}$ was purchased from IBA. A baseline ${ }^{18} \mathrm{~F}-\mathrm{FDG}$ PET/CT was performed on day 0 to ensure that the subject mice have no baseline bowel pathology that enhanced glucose uptake.
The DSS-treated $(n=4)$ and control mice $(n=4)$ with CT26 s.c allografts were imaged with ${ }^{18} \mathrm{~F}-\mathrm{FDG}$ and ${ }^{64} \mathrm{Cu}$-DOTA-cetuximab-F(ab')2 PET/CT and tumor to bowel ratios were compared between the DSS-treated mice and control group for both radiotracers $\left({ }^{18} \mathrm{~F}-\mathrm{FDG}\right.$ and ${ }^{64} \mathrm{Cu}$-DOTA-cetuximab-F( $\left.\left(\mathrm{ab}^{\prime}\right) 2\right)$.

Conditional knockout mice with $A p c^{C K O} p 53^{f l o x} / f l o x$ and $A p c^{\text {LoxP/ }} \operatorname{LoxP}_{\text {Msh }} 2^{\text {null/LoxP }}$ mutation underwent whole body PET/CT imaging $24 \mathrm{hr}$ after intravenous ${ }^{64} \mathrm{Cu}$-DOTA-cetuximab-F( $\left(\mathrm{ab}^{\prime}\right) 2$ injection. The colons of the mice were extracted immediately after whole body PET/CT and were placed in the PET/CT scanner for ex vivo imaging. The static ex vivo PET/CT images from these colons were overlaid on the gross white light photographs of the colons in the same position and orientation.

\section{Histological analysis}

Mice were euthanized and the colons were removed, and cleaned in physiological saline solution to remove fecal residue. They were fixed in neutrally buffered 10\% formalin at room temperature for $48 \mathrm{hr}$ before they were embedded in paraffin and sectioned. All tissues were stained with hematoxylin and eosin (H\&E) for histological evaluation. Light microscopy was performed with an Olympus IX51 microscope.

Immunohistochemical (IHC) analysis was performed on CT26 tumor allografts, and colon tissue samples as described previously ${ }^{1,7}$. Briefly, unstained $5 \mu \mathrm{m}$ sections were cut, deparaffinized and rehydrated by standard techniques before antigen retrieval in EDTA buffer. The samples were then incubated in a 1:50 dilution of anti-EGFR rabbit polyclonal IgG (Santa Cruz Biotechnology, Inc., Santa Cruz, CA, USA) overnight at $4{ }^{\circ} \mathrm{C}$. The sections were washed in TBST and incubated with biotinylated goat anti-rabbit IgG (H+L) (Abcam, Cambridge, MA, USA) for $1 \mathrm{hr}$. The staining was developed using the DAKO Liquid $\mathrm{DAB}+$ substrate chromogen system (Dako, Carpinteria, CA, USA) for $1 \mathrm{~min}$. Slides were washed in water and counterstained with hematoxylin and dehydrated before mounting.

\section{Statistics}

Statistical analysis was performed using Prism software (Graphpad, San Diego, USA). Differences in uptake of the tracers were tested for significance using the t-test. P-values of 0.05 were considered significant. Data are represented as mean \pm standard error of the mean (SEM).

\section{Results}

\section{Radiotracer preparation and characterization}

$\mathrm{F}\left(\mathrm{ab}^{\prime}\right) 2$ fragment of cetuximab was produced through enzymatic digestion as shown in Figure 1A. 
$\mathrm{F}\left(\mathrm{ab}^{\prime}\right) 2$ was generated with high purity $(>98 \%)$ and $1.2 \mathrm{mg} \mathrm{F}\left(\mathrm{ab}^{\prime}\right) 2$ was recovered from $2 \mathrm{mg}$ of antibody $(\sim 60 \%$ yield). The size-exclusion FPLC and SDS-PAGE results demonstrated that pure $F\left(a b^{\prime}\right) 2$ fragment of cetuximab was obtained after the digestion of intact IgG with enzymatic digestion and followed by protein A purification (Figure $1 \mathrm{~B} \& \mathrm{C}$ ). Whole antibody appears at $180 \mathrm{~min}$, while $\mathrm{F}\left(\mathrm{ab}^{\prime}\right) 2$ appears at $202 \mathrm{~min}$ and $\mathrm{FC}_{\mathrm{C}}$ appears at $235 \mathrm{~min}$ (Figure 1B). Reaction of cetuximab $F\left(a^{\prime}\right) 2$ with a 10-fold excess of p-SCN-Bn-DOTA resulted in substitution of approximately 1 DOTA chelate per $\mathrm{F}\left(\mathrm{ab}^{\prime}\right) 2$. The labeling efficiency for ${ }^{64} \mathrm{Cu}-\mathrm{DOTA}$-cetuximab-F( $\left(\mathrm{ab}^{\prime}\right) 2$ was $60 \pm 5 \%$ and with $\geq 99 \%$ radiochemical purity (Figure 1D). The specific activity of ${ }^{64} \mathrm{Cu}$-DOTAcetuximab-F( $\left(\mathrm{ab}^{\prime}\right) 2$ was $19.5 \pm 6.8 \mathrm{mCi} / \mathrm{mg}$ cetuximab.

We observed that CT26 murine colon cancer cell line has high EGFR expression, comparable to that of high EGFR expressing HCT-116 human colorectal cancel line as shown in Western blot analysis (Figure $1 F)$. Direct (saturation) radioligand binding assays

A

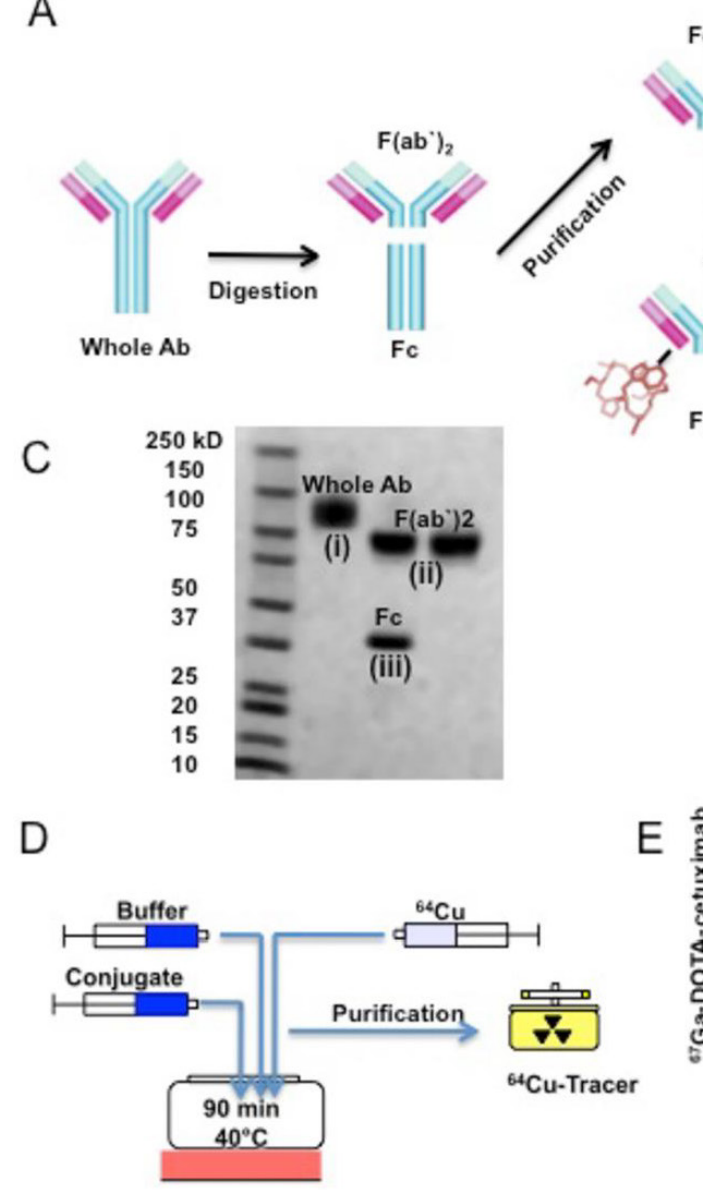

showed that ${ }^{64} \mathrm{Cu}$-DOTA-cetuximab-F( $\left(\mathrm{ab}^{\prime}\right) 2$ bound specifically to EGFR on CT26 cells (Figure 1E). The $K_{D}$ value for ${ }^{64} \mathrm{Cu}$-DOTA-cetuximab-F( $\left(\mathrm{ab}^{\prime}\right) 2$ was $6.6 \pm 0.7$ $\mathrm{nM}$ and the $\mathrm{B}_{\max }$ value on CT26 cells was $3.3 \pm 0.1 \times 10^{6}$ receptors/cell. A representative competitive binding curve of ${ }^{64} \mathrm{Cu}$-DOTA-cetuximab-F $\left(\mathrm{ab}^{\prime}\right) 2$ is shown in Figure 1E.

\section{The ${ }^{64} \mathrm{Cu}$-DOTA-cetuximab-F(ab')2 is specific for EGFR in vivo}

The specificity of ${ }^{64} \mathrm{Cu}$-DOTA-cetuximab-F( $\left(\mathrm{ab}^{\prime}\right) 2$ for EGFR was confirmed by in vivo blocking studies (Figure 2). Administering a blocking dose of cetuximab the tumor uptake was significantly reduced (SUV of $0.31 \pm 0.04$ (non-blocking) vs. $0.15 \pm 0.02$ (blocking), $\mathrm{n}=4 ; \mathrm{P}<0.05$ ) and (tumor to muscle SUV of $6.64 \pm 0.85$ (non-blocking) vs. $2.56 \pm 1.87$ (blocking), $\mathrm{n}=4 ; \mathrm{P}<0.05)$ which demonstrated that ${ }^{64} \mathrm{Cu}-\mathrm{DOTA}-$ cetuximab-F( $\left(\mathrm{ab}^{\prime}\right) 2$ maintained EGFR specificity in vivo.

B
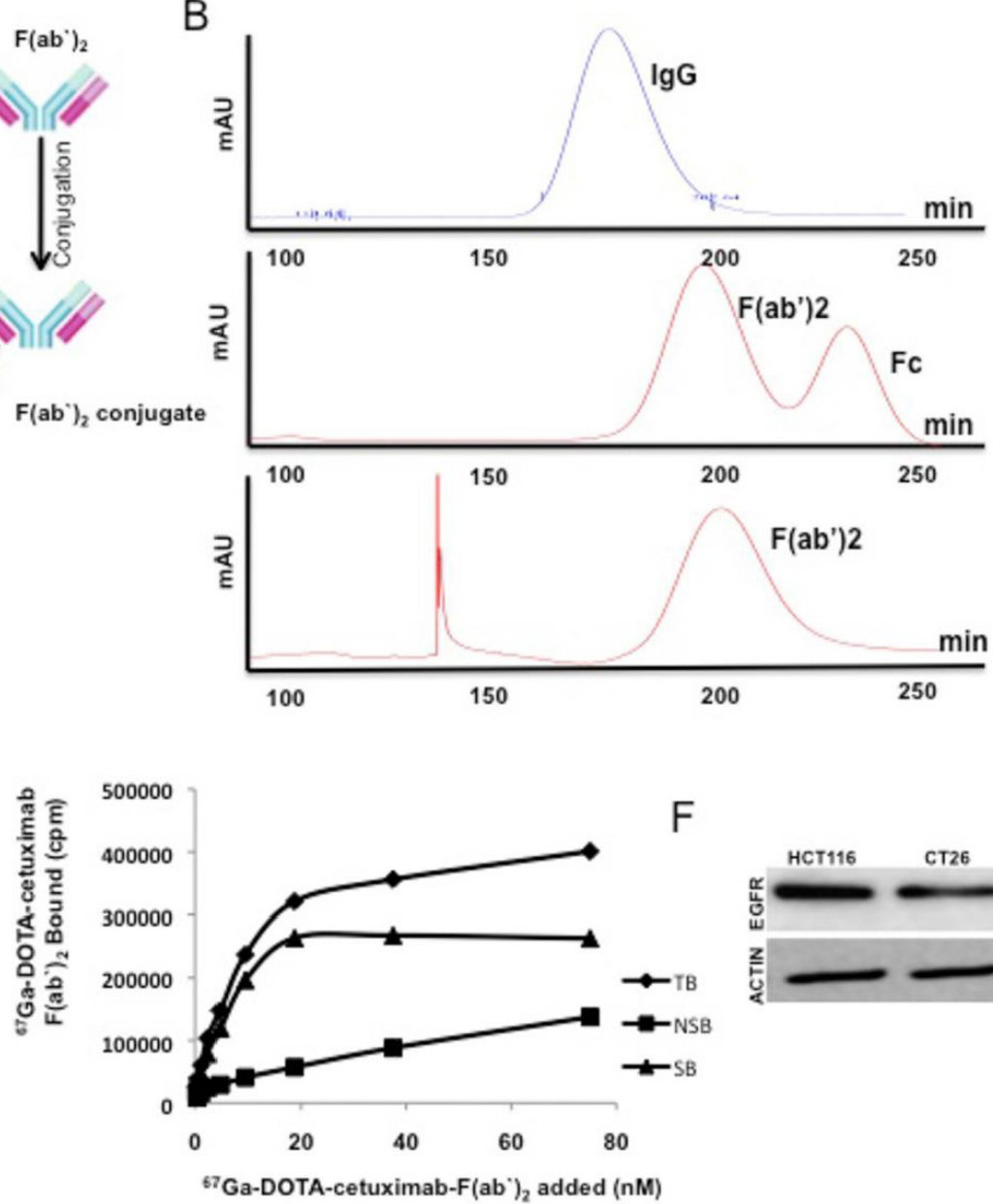

Figure I. A schematic overview of the EGFR targeted PET probe synthesis and characterization. (A) Enzymatic fragmentation of whole antibody and conjugation of F(ab')2 fragment with bifunctional chelator. (B) FPLC chromatograms of whole lgG before digestion, after digestion, and after protein A purification. (C) SDS-PAGE analysis of enzymatic digestion of cetuximab lgG. (i) Whole antibody before digestion; (ii) $F(a b$ ') 2 and Fc bands after digestion of whole antibody; (iii) $F(a b$ ') 2 band after protein $A$ purification. (D)

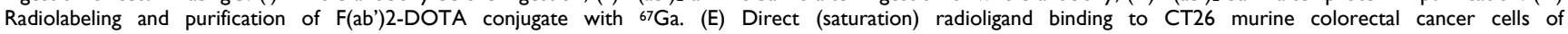
${ }^{64} \mathrm{Cu}$-DOTA-cetuximab-F(ab')2, in the absence (total binding; TB) or presence (non-specific binding; NSB) of excess ( 20 times) unlabeled cetuximab IgG. Specific binding (SB) was calculated by subtraction of NSB from TB. Curves were fit to a I-site receptor-binding model. $\boldsymbol{\nabla}=\mathrm{TB} ; \boldsymbol{\nabla}=\mathrm{NSB} ; \boldsymbol{\Delta}=\mathrm{SB}$. (F) Western blot of EGFR expression in CT26 and HCT-II 6 colon cancer cell lines with beta-actin as control, demonstrate EGFR overexpression. 


\section{A}

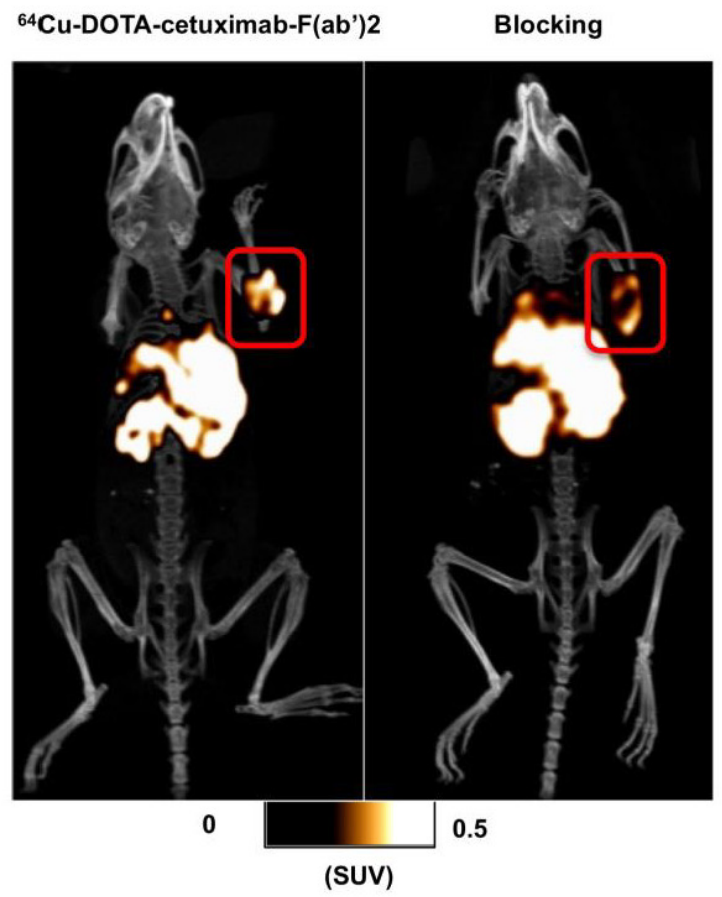

B
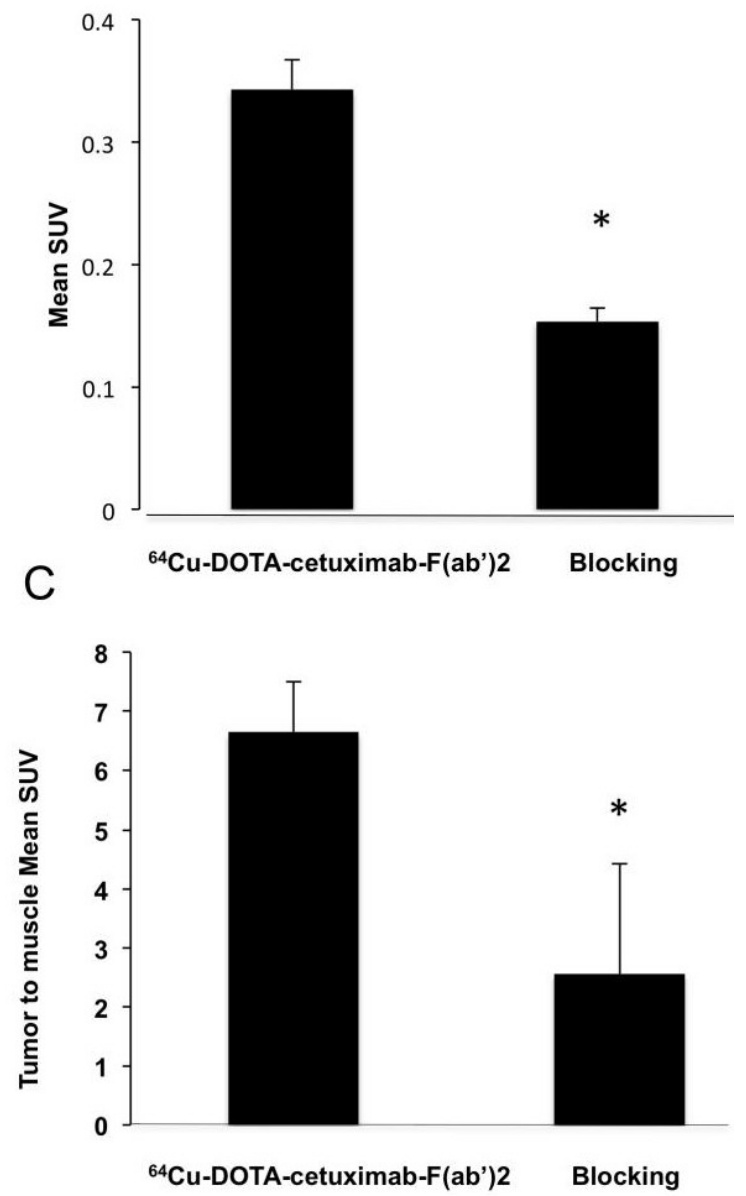

Figure 2. PET imaging of EGFR expression in BALB/c mice at $24 \mathrm{hr}$ post injection of ${ }^{64} \mathrm{Cu}$-DOTA-cetuximab-F(ab') 2 or ${ }^{64} \mathrm{Cu}-\mathrm{DOT}$ $\mathrm{mg}$ blocking dose of cetuximab. A) Example images without and with blocking. Red circles highlight site of implanted CT26 tumor allograft B) Comparison of MeanSUV values of ${ }^{64}$ Cu-DOTA-cetuximab-F(ab')2 without and with blocking. Each bar represents SUVmean $\pm S E M ; n=4$ for each group, and the symbol $*$ denotes $P<0.05$. C) Comparison of tumor to muscle ratios of ${ }^{64} \mathrm{Cu}$-DOTA-cetuximab- $\mathrm{F}\left(\mathrm{ab} \mathrm{b}^{\prime}\right) 2$ without and with blocking. Each bar represents SUVmean $\pm S E M ; n=4$ for each group, and the symbol $*$ denotes $P<0.05$.

\section{The DSS induced colitis model}

Body weight loss was used to monitor colitis. The body weight loss gave a peak on day 8 (Figure $3 \mathrm{~A})$. The body weight was significantly decreased (23.35 $\pm 0.11 \mathrm{~g}$ (day 0) vs. $20.45 \pm 0.64 \mathrm{~g}$ (DSS-treated, day 8 ) and $23.35 \pm 0.11 \mathrm{~g}$ (day 0) vs. $20.35 \pm 0.21$ (DSS-treated, day 10), $\mathrm{n}=4, P<0.05)$ after DSS treatment. PET imaging was performed on control and DSS-treated mice to assess the effects of colitis on 18F-FDG colonic uptake after DSS treatment. The arrows on the images indicate the high characteristic accumulation of ${ }^{18} \mathrm{~F}-\mathrm{FDG}$ in the inflamed areas of DSS-treated mice (Figure 3B). ${ }^{18} \mathrm{~F}-\mathrm{FDG}$ PET/CT scans showed significant increase in uptake $(0.22 \pm 0.02$ $\% \mathrm{ID} / \mathrm{g}$ (control) vs. $0.43 \pm 0.09 \% \mathrm{ID} / \mathrm{g}$ (DSS-treated, day 9), $n=4, P<0.05)$ in the colons of the DSS-treated groups.

Histological examination of the normal colon showed normal mucosal architecture. Mucin loss, loss of crypt architecture and intraepithelial inflammation was observed in the colon of mice that received DSS treatment for seven days (Figure 3C).

\section{PET/CT imaging}

In a subset of control and DSS-treated BALB/C mice implanted with CT26 allografts imaging was performed sequentially with both ${ }^{18} \mathrm{~F}-\mathrm{FDG}$ and ${ }^{64} \mathrm{Cu}$-DOTA-cetuximab- $\mathrm{F}\left(\mathrm{ab}^{\prime}\right) 2$ to compare the tumor to bowel radiotracer uptake ratios (Figure 4A). The tumor to bowel ratio was significantly decreased (3.95 \pm 0.13 (control) vs. $1.54 \pm 0.08$ (DSS-treated), $n=4$, $P<0.05)$ in DSS-treated mice imaged with ${ }^{18}$ F-FDG. However there was no significant difference (4.42 \pm 0.11 (control) vs. $3.78 \pm 0.06$ (DSS-treated), $\mathrm{n}=4$, $P=0.22$ ) in the tumor to bowel ratio between the control and the DSS-treated mice imaged with ${ }^{64} \mathrm{Cu}$ DOTA-cetuximab-F(ab')2. ${ }^{64} \mathrm{Cu}$-DOTA-cetuximab$\mathrm{F}\left(\mathrm{ab}^{\prime}\right) 2$ also showed significantly higher $(3.78 \pm 0.06$ $\left({ }^{64} \mathrm{Cu}-\mathrm{DOT} A-c e t u x i m a b-\mathrm{F}\left(\mathrm{ab}^{\prime}\right) 2\right)$ vs. $1.54 \pm 0.08$ 
$\left.\left({ }^{18} \mathrm{~F}-\mathrm{FDG}\right), \mathrm{n}=4 ; P<0.05\right)$ tumor to bowel ratio in comparison with ${ }^{18} \mathrm{~F}-\mathrm{FDG}$ in DSS-induced mice (Figure $4 \mathrm{~B})$.

${ }^{64} \mathrm{Cu}$-DOTA-cetuximab-F(ab')2 whole body PET/CT images of mice with Apc CKOP53flox/flox and $A p c^{L o x P / L o x P} M s h 2^{\text {null/LoxP }}$ mutations revealed focal areas of high uptake in colonic adenomas. After the PET/CT imaging, the colons were excised and imaged ex vivo with PET/CT. An anatomic correlation between the location of visible adenoma foci and areas of high uptake in ex vivo ${ }^{64} \mathrm{Cu}$-DOTAcetuximab-F( $\left(\mathrm{b}^{\prime}\right) 2 \mathrm{PET} / \mathrm{CT}$ images was noted. (Figure $5 A \& B)$.

A

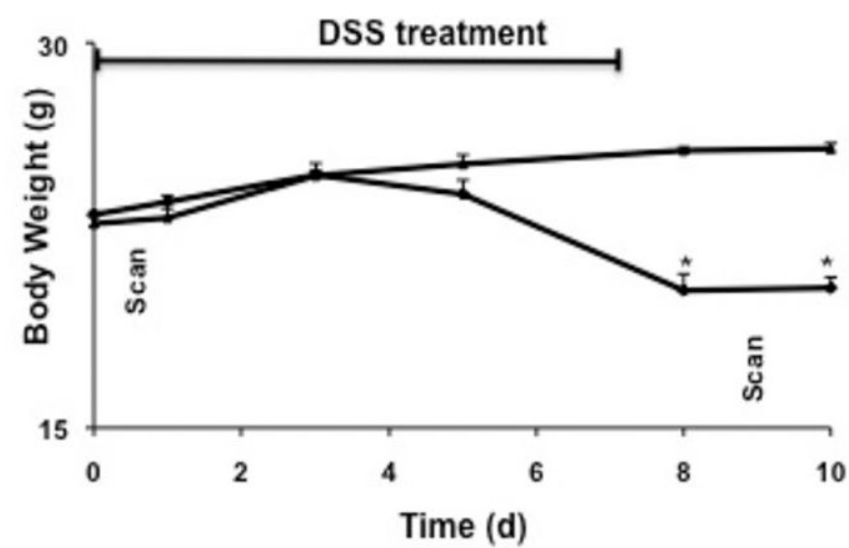

C

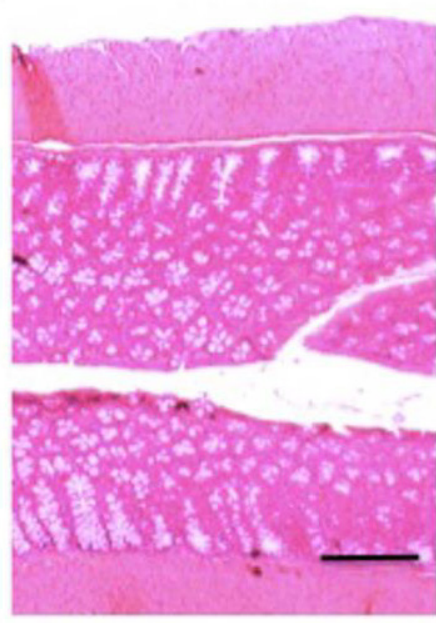

Control

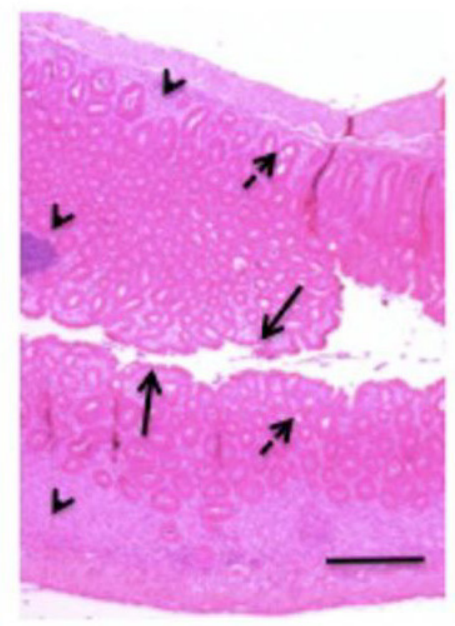

Colitis

\section{Histopathologic analysis}

H\&E and IHC stained tissue sections of mice are shown in Figure 6. Normal colonic mucosa with crypt architecture, along with modulation seen with DSS-treatment, and characteristic features in the adenomas are noted (Figure 6A). Membranous brown staining of cells above the background level was defined as EGFR positive. IHC staining for EGFR revealed very weak staining in control and DSS-treated colonic tissue, while strong EGFR staining was observed with CT26 allograft and colon tumors from

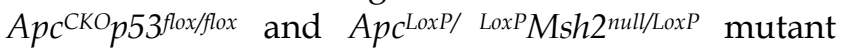
mice (Figure 6B). Interestingly, the level of IHC staining for EGFR for the adenomatous lesions visually corresponds with the level of vivo ${ }^{64} \mathrm{Cu}$-DOTA-cetuximab-F( $\left(\mathrm{ab}^{\prime}\right) 2$ uptake in the ex vivo samples (Figure 5).
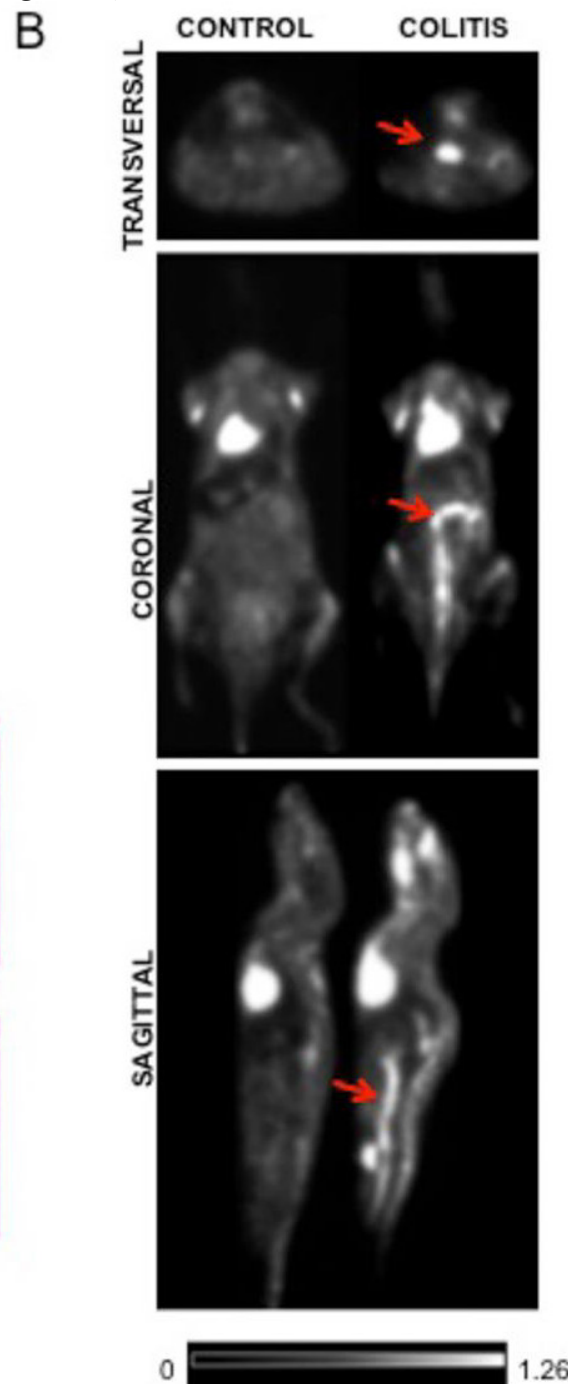

(SUV)

Figure 3. Assessment of symptoms and histological findings of DSS-treated and control mice. BABL/c mice were subjected to $3 \%$ DSS for seven days and followed with normal drinking water for three days. (A) Body weight changes following DSS induction of colitis, reported as mean \pm SEM ( $n=4$ mice/group) and the symbol $*$ denotes $P<0.05$. (B) microPET-CT scans were obtained before and after DSS treatment. Before DSS treatment, PET showed only low level of physiologic $18 \mathrm{~F}$-FDG uptake in the colon of healthy controls. In contrast, on day nine, clearly elevated 18 F-FDG colonic uptake is noted (red arrow). (C) Histological appearance of the normal colonic mucosa of healthy controls with intact crypts and architecture (control) and DSS-induced colitis showing inflammatory infiltration (arrow head), mucin loss (arrow) and crypt architectural disarray (dashed arrow). Magnification $\times 20$ and scale bar represents $100 \mu \mathrm{m}$. 
A

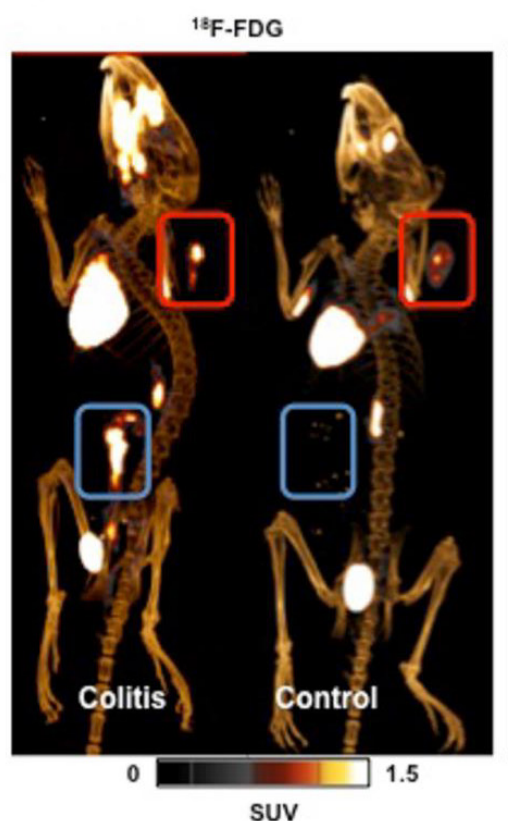

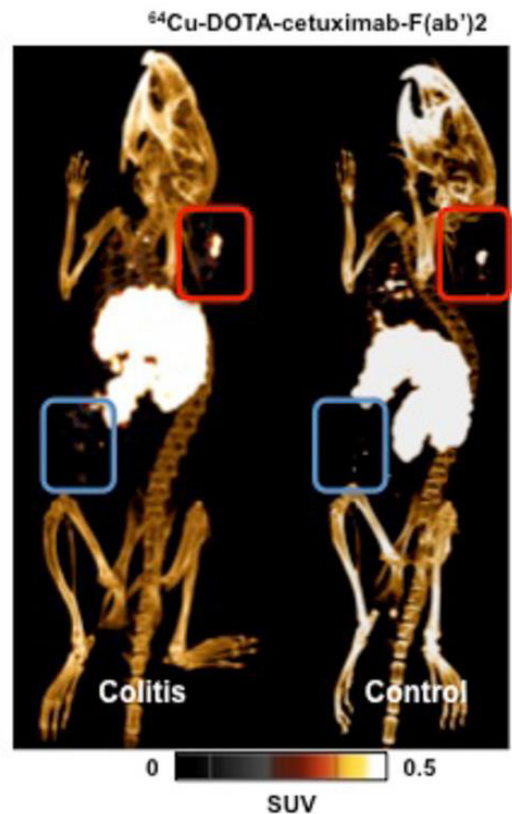

B

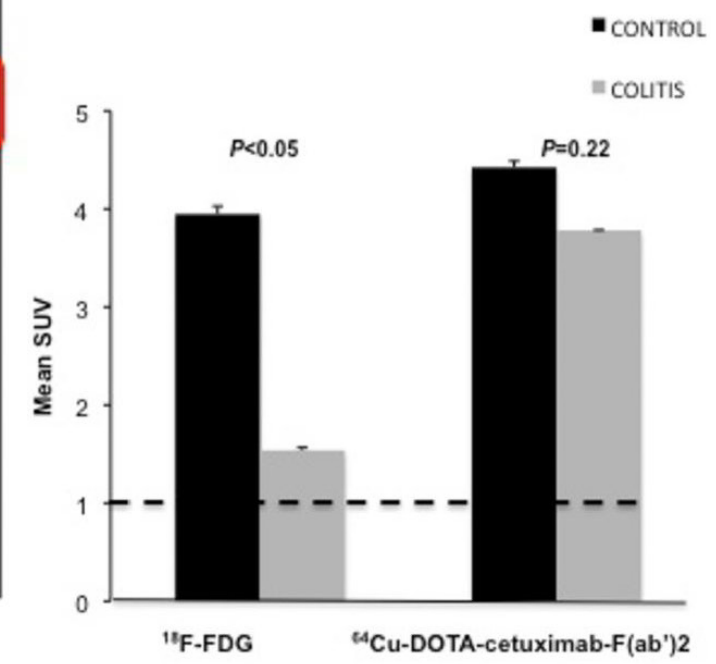

Figure 4. Comparison of PET imaging with ${ }^{18} \mathrm{~F}-\mathrm{FDG}$ and ${ }^{64} \mathrm{Cu}-\mathrm{DOTA}$-cetuximab-F(ab')2 in CT26 tumor-bearing mice with and without DSS-induced colitis. (A) PET-CT images were performed I hr after ${ }^{18} \mathrm{~F}-\mathrm{FDG}$ and $24 \mathrm{hr}$ after ${ }^{64} \mathrm{Cu}$-DOTA-cetuximab-F(ab') 2 administration. Representative images from a mouse are shown, with $\mathrm{n}=4 \mathrm{mice}$ imaged in each group. Red squares indicate the location of tumors and blue squares indicate location of DSS-induced colitis. (B) Comparison of tumor to colon ratios at $24 \mathrm{hr}$ post-injection. Each bar represents SUVmean \pm SEM; $n=4$ for each group. The symbol $*$ denote $P<0.05$ and the difference is not significant $(P=0.22)$ for ${ }^{64 C u}-D O T A-c e t u x i m a b-F(a b ') 2$. The dash line verifies TBR=I (no contrast).

\section{Discussion}

Persistent inflammation in the colon seen in IBD is correlated with increased cell proliferation, dysplasia, and the subsequent development of $\mathrm{CRC}^{4,29-31}$. The mortality of IBD associated CRC has remained high over the last 20 years, in part due to the approximately $50 \%$ of CRC that were not detected until an advanced stage ${ }^{32}$. Therefore there is a clear need to develop new screening strategies that are more sensitive and less cumbersome than current approaches for high-risk patients. While the noninvasive nature of PET scanning greatly improves tolerance, colonic inflammation that is a hallmark of IBD affecting the colon makes noninvasive screening for cancer using 18F-FDG PET somewhat less useful in the IBD setting, given the known uptake of the radiotracer in inflammatory as well as neoplastic cells. We hypothesized that EGFR would be an appropriate target for imaging, highlighting tumor even in the setting of colitis, given its high expression seen in the large majority of CRC, and the lack of overexpression noted in normal colonic mucosa and in the inflammatory cells associated with chronic colitis. We thus developed an EGFR targeting PET imaging agent based on the $\mathrm{F}\left(\mathrm{ab}^{\prime}\right) 2$ fragment of cetuximab conjugated to the chelator DOTA and labeled with the radiometal ${ }^{64} \mathrm{Cu}$. We chose the $F\left(a b^{\prime}\right) 2$ fragments as the basis for the imaging agent given the improved target to background ratio (TBR) relative to whole antibodies 33 , and im- proved pharmacokinetics for translation 16,34 . The developed imaging agent is translatable for human studies given the high safety profile of the parent antibody, and the components have all been utilized in prior clinical translation. PET imaging agents have an advantage of an extremely low mass of injection given the high sensitivity of PET detection, and thus a broad range of agents have been translated to human evaluation $^{35}$. Finally, as new algorithms are developed for image reconstruction and with the introduction of PET-MR clinical scanners, the radiation dose associated with PET imaging continues to decrease, making this potential approach more appealing ${ }^{36}$. While very low bowel uptake was seen in these preclinical studies in both normal and colitis settings, given the known hepatic clearance, early translational studies will help confirm that low signal from bowel remains in the clinical setting.

Monoclonal antibodies are widely used as therapeutics. However, their long circulation time typically in the range of days to weeks, and the potential for immune response, make their use as imaging agents less ideal ${ }^{37-39}$. Bivalent $\mathrm{F}\left(\mathrm{ab}^{\prime}\right) 2$ antibody fragments have a shorter blood clearance, higher tumor to background ratios at early time points, reduced non-specific distribution, and lower immunogenicity relative to whole antibodies, while retaining the advantage of increased affinity associated with bivalency ${ }^{16}, 40$. The developed imaging probe has a high 
affinity of $6.6 \mathrm{nM}$ for EGFR. We chose a radioisotope, ${ }^{64} \mathrm{Cu}\left(\mathrm{t}_{1 / 2}=12.7 \mathrm{~h}\right)$, that matched the pharmacokinetics of the $\mathrm{F}\left(\mathrm{ab}^{\prime}\right) 2$ antibody fragment ${ }^{39}$. We demonstrated that the EGFR targeting probe was able to image both allografts (CT26 tumors) as well as spontaneous colonic adenomas in two different GEM models

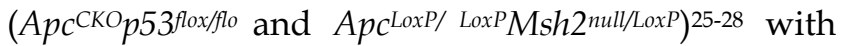
high standard uptake values (SUV). In the previous studies, Western blots of EGFR expression on human and murine cell lines showed that cetuximab strongly binds to the murine cell line CT2641. GEM models are selected to provide a platform for studying CRC from certain mutations such Apc and p53. Apc CKOp53flox/flo and $A p c^{{ }^{L o x P} / L o x P} M s h 2^{\text {null/LoxP }}$ GEM models were selected
A1

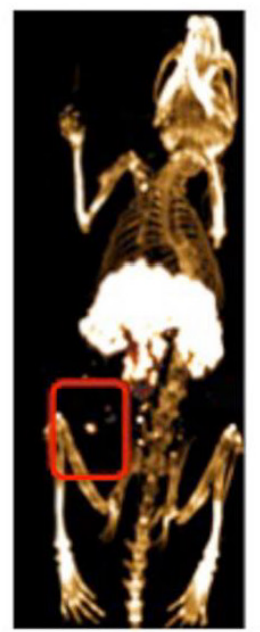

B1

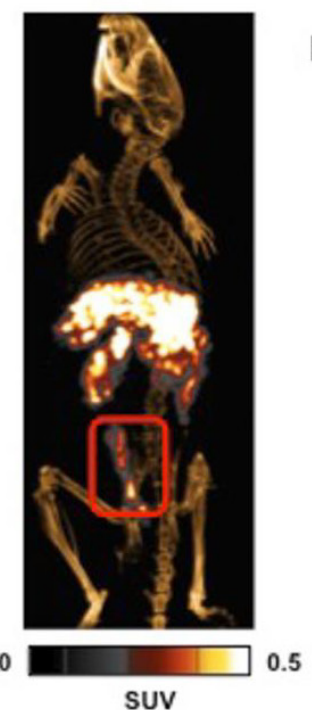

A2

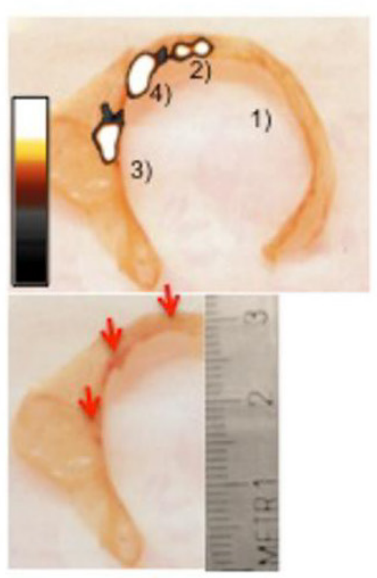

B2

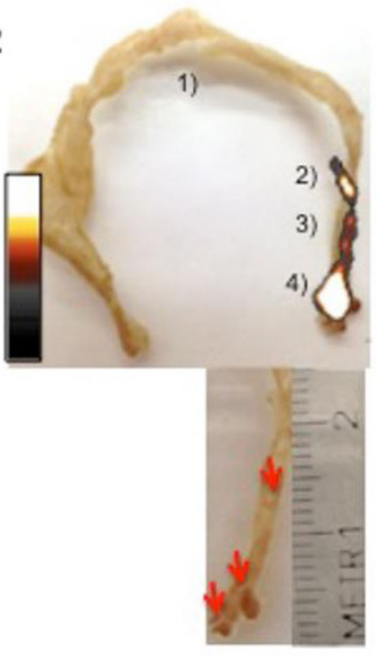

for this study because Apc and Msh2 processes are often deranged in large numbers of CRCs in the setting of IBD 42,43 . The EGFR targeted probe uptake in spontaneous lesions in representative mouse models of colonic adenomas further points to the translational potential of this approach. Both ${ }^{18} \mathrm{~F}-\mathrm{FDG}$ and ${ }^{64} \mathrm{Cu}$-DOTA-cetuximab- $\mathrm{F}\left(\mathrm{ab}^{\prime}\right) 2$ demonstrated high TBR for tumor uptake relative to normal colon. However, the EGFR targeting probe retained a high TBR in the setting of colitis, whereas the TBR markedly decreased for ${ }^{18} \mathrm{~F}-\mathrm{FDG}$ to approximately 1.5 in the setting of bowel inflammation, largely due to the expected increase in ${ }^{18} \mathrm{~F}-\mathrm{FDG}$ uptake in the inflamed bowel.

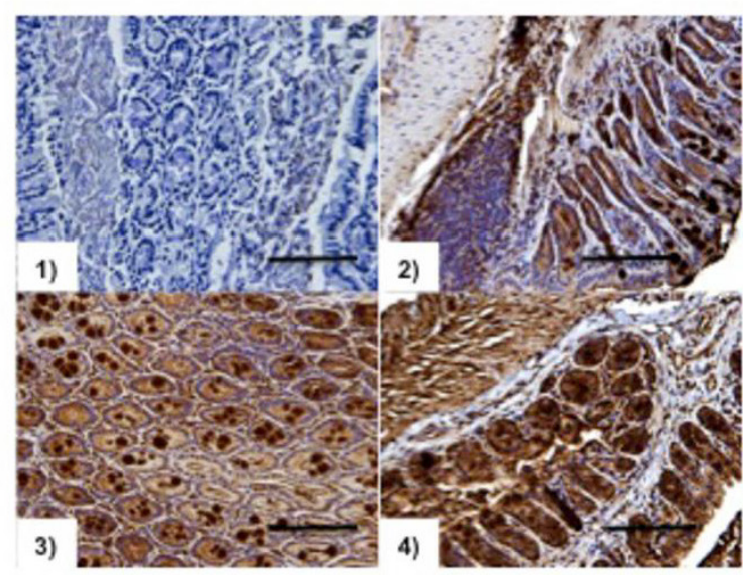

B3

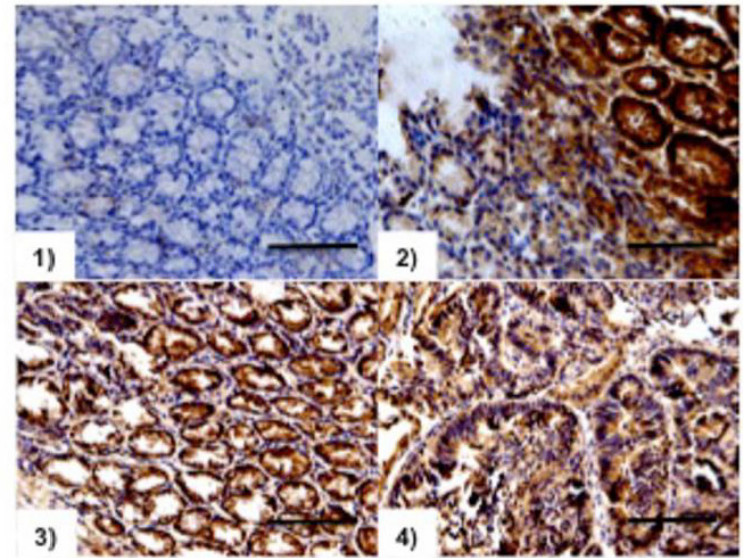

Figure 5. Correlation between EGFR targeted PET imaging and EGFR immunohistochemistry. (AI) PET imaging of ApcCKOP53flox/flox mouse with ${ }^{64}$ Cu-DOTA-cetuximab-F(ab')2 at $24 \mathrm{hr}$. (A2) The digital photograph of colon and the colon fused with the ex-vivo PET image. (A3) Corresponding EGFR expression patterns of different colon sections numbered in A2 are confirmed with immunohistochemistry (magnification $\times 20$ ). (BI) Representative images of decay corrected PET image of ApcLoxP/ LoxPMsh2null/LoxP mutant mice after the injection of ${ }^{64} \mathrm{Cu}-\mathrm{DOTA}$-cetuximab-F(ab') 2 at $24 \mathrm{hr}$. (B2) The digital photograph of colon and the colon fused with the ex-vivo PET image. (B3) EGFR expression patterns of different colon sections numbered in B2 are confirmed with immunohistochemistry (magnification $\times 20$ ). Scale bar represents $50 \mu \mathrm{m}$. 

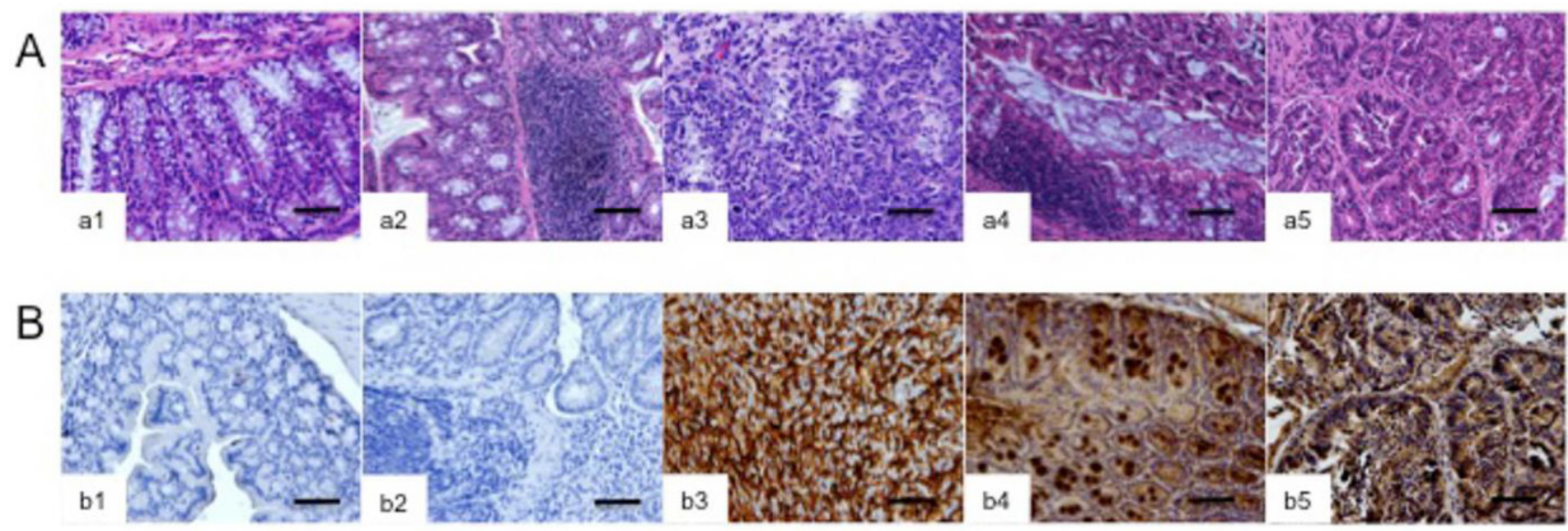

Figure 6. H\&E and IHC analysis were examined to compare the histological changes in colons from healthy, DSS-treated, GEM models and allograft (CT26 tumor). IHC results demonstrate that there is no significant EGFR expression in healthy and DSS-treated colons, while there is strong staining in allograft and GEM model colonic lesions. (A) Representative H\&E tissue sections from (al) healthy colon, (a2) DSS-treated colon, (a3) CT26 allograft, (a4) ApcCKOP53flox/flox mutant mouse colon, (a5) ApcloxPlloxPMsh2null/LoxP mutant mouse colon. (B) IHC analysis of EGFR from tissues of (bl) healthy colon, (b2) DSS-treated colon, (b3) CT26 allograft, (b4) Apc CKOP53flox/fox mutant mouse colon, (b5) Apc LoxP/ LoxPMsh2 $2^{\text {null/LoxP }}$ mutant mouse colon. Scale bar represents $50 \mu \mathrm{m}$.

A large percentage of IBD-associated cancers have immunohistochemical positivity for EGFR and strong EGFR intensity has been associated with higher tumor staging $44,45,46$. Our results show a strong correlation between whole body PET-CT EGFR-targeted imaging, ex-vivo EGFR-based PET imaging of the colon, and histopathological findings of the degree of EGFR expression. The visualized weak EGFR staining of healthy colon is likely secondary to the limited EGFR expression in the basolateral surface of the colon ${ }^{23}$. We additionally confirmed the previously reported weak EGFR staining for DSS-induced colitis ${ }^{47}$. High EGFR staining was clearly visualized in the CT26 allograft and colorectal adenomas in the GEMM. It has been previously noted that the mean specific EGFR intensity in neoplasia is approximately ten times higher than in normal mu$\operatorname{cosa}^{12}$. Given the high correlation between lesion EGFR expression and uptake of the developed ${ }^{64} \mathrm{Cu}-\mathrm{DOTA}-\mathrm{F}\left(\mathrm{ab}^{\prime}\right) 2$ PET imaging probe, the approach may be useful not only for detection, but also for anti-EGFR treatment monitoring.

\section{Conclusions}

A clinically translatable ${ }^{64} \mathrm{Cu}$-DOTA-cetuximab$\mathrm{F}\left(\mathrm{ab}^{\prime}\right) 2$ PET imaging probe was successfully developed to assess EGFR noninvasively. The imaging agent can detect colonic tumors with a high target to background ratio in the setting of colitis. This approach offers improved imaging characteristics compared to standard ${ }^{18}$ F-FDG PET imaging for detection of in situ lesions in the setting of IBD, and opens the possibility for a new approach for screening high-risk patients for the development of CRC in the setting of colonic inflammation.

\section{Acknowledgements}

This study was supported by U01CA084301, P50CA127003, and U01CA143056. N. Selcan Turker supported by the Dubai Harvard Foundation for Medical Research (DHFMR, grant number: 223439).

\section{Competing Interests}

The authors have declared that no competing interest exists.

\section{References}

1. Lissner D, Siegmund B. Ulcerative colitis: current and future treatment strategies. Dig Dis 2013;31:91-4.

2. Burisch J, Munkholm P. Inflammatory bowel disease epidemiology. Curr Opin Gastroenterol 2013;29:357-62.

3. O'Connor OJ, McDermott S, Slattery J, et al. The Use of PET-CT in the Assessment of Patients with Colorectal Carcinoma. Int J Surg Oncol 2011;2011:846512.

4. Ahmadi A, Polyak S, Draganov PV. Colorectal cancer surveillance in inflammatory bowel disease: the search continues. World J Gastroenterol 2009;15:61-6.

5. Kiesslich R, Fritsch J, Holtmann M, et al. Methylene blue-aided chromoendoscopy for the detection of intraepithelial neoplasia and colon cancer in ulcerative colitis. Gastroenterology 2003;124:880-8.

6. Bernstein CN, Weinstein WM, Levine DS, et al. Physicians' perceptions of dysplasia and approaches to surveillance colonoscopy in ulcerative colitis. Am J Gastroenterol 1995;90:2106-14.

7. Higashikawa K, Akada N, Yagi K, et al. Exploration of target molecules for molecular imaging of inflammatory bowel disease. Biochem Biophys Res Commun 2011;410:416-21.

8. Bettenworth D, Reuter S, Hermann S, et al. Translational 18F-FDG PET/CT imaging to monitor lesion activity in intestinal inflammation. J Nucl Med 2013;54:748-55.

9. Berthold LD, Steiner D, Scholz D, et al. Imaging of chronic inflammatory bowel disease with 18F-FDG PET in children and adolescents. Klin Padiatr 2013;225:212-7.

10. Perlman SB, Hall BS, Reichelderfer M. PET/CT imaging of inflammatory bowel disease. Semin Nucl Med 2013;43:420-6.

11. Mahmood U. Optical molecular imaging approaches in colorectal cancer. Gastroenterology 2010;138:419-22.

12. Goetz M, Ziebart A, Foersch S, et al. In vivo molecular imaging of colorectal cancer with confocal endomicroscopy by targeting epidermal growth factor receptor. Gastroenterology 2010;138:435-46.

13. Heinemann V, Stintzing S, Kirchner T, et al. Clinical relevance of EGFR- and KRAS-status in colorectal cancer patients treated with monoclonal antibodies directed against the EGFR. Cancer Treat Rev 2009;35:262-71. 
14. Hoetker MS, Kiesslich R, Diken M, et al. Molecular in vivo imaging of gastric cancer in a human-murine xenograft model: targeting epidermal growth factor receptor. Gastrointest Endosc 2012;76:612-20

15. Dube PE, Yan F, Punit S, et al. Epidermal growth factor receptor inhibits colitis-associated cancer in mice. J Clin Invest 2012;122:2780-92.

16. Wong KJ, Baidoo KE, Nayak TK, et al. In Vitro and In Vivo Pre-Clinical Analysis of a $\mathrm{F}\left(\mathrm{ab}^{\prime}\right)(2)$ Fragment of Panitumumab for Molecular Imaging and Therapy of HER1 Positive Cancers. EJNMMI Res 2011;1.

17. Cooper MS, Ma MT, Sunassee K, et al. Comparison of (64)Cu-Complexing Bifunctional Chelators for Radioimmunoconjugation: Labeling Efficiency, Specific Activity, and in Vitro/in Vivo Stability. Bioconjug Chem 2012.

18. Ferreira CL, Yapp DT, Crisp S, et al. Comparison of bifunctional chelates for (64) $\mathrm{Cu}$ antibody imaging. Eur J Nucl Med Mol Imaging 2010;37:2117-26.

19. Chan C, Scollard DA, McLarty K, et al. A comparison of 111In- or 64Cu-DOTA-trastuzumab Fab fragments for imaging subcutaneous HER2-positive tumor xenografts in athymic mice using microSPECT/CT or microPET/CT. EJNMMI Res 2011;1:15.

20. Ferreira CL, Lamsa E, Woods M, et al. Evaluation of Bifunctional Chelates for the Development of Gallium-Based Radiopharmaceuticals. Bioconjug Chem 2010.

21. Ferreira CL, Yapp DT, Mandel D, et al. (68)Ga small peptide imaging: comparison of NOTA and PCTA. Bioconjug Chem 2012;23:2239-46.

22. Miao Z, Ren G, Liu H, et al. Small-animal PET imaging of human epidermal growth factor receptor positive tumor with a $64 \mathrm{Cu}$ labeled affibody protein. Bioconjug Chem 2010;21:947-54.

23. Playford RJ, Hanby AM, Gschmeissner S, et al. The epidermal growth factor receptor (EGF-R) is present on the basolateral, but not the apical, surface of enterocytes in the human gastrointestinal tract. Gut 1996;39:262-6.

24. Whittem CG, Williams AD, Williams CS. Murine Colitis modeling using Dextran Sulfate Sodium (DSS). J Vis Exp 2010.

25. Martin ES, Belmont PJ, Sinnamon MJ, et al. Development of a colon cancer GEMM-derived orthotopic transplant model for drug discovery and validation. Clin Cancer Res 2013;19:2929-40.

26. Hung KE, Maricevich MA, Richard LG, et al. Development of a mouse model for sporadic and metastatic colon tumors and its use in assessing drug treatment. Proc Natl Acad Sci U S A 2010;107:1565-70.

27. Kucherlapati MH, Lee K, Nguyen AA, et al. An Msh2 conditional knockout mouse for studying intestinal cancer and testing anticancer agents. Gastroenterology 2010;138:993-1002 e1.

28. Kuraguchi M, Wang XP, Bronson RT, et al. Adenomatous polyposis coli (APC) is required for normal development of skin and thymus. PLoS Genet 2006;2:e146.

29. Fujii S, Fujimori T, Kawamata H, et al. Development of colonic neoplasia in p53 deficient mice with experimental colitis induced by dextran sulphate sodium. Gut 2004;53:710-6.

30. Eaden JA, Abrams KR, Mayberry JF. The risk of colorectal cancer in ulcerative colitis: a meta-analysis. Gut 2001;48:526-35.

31. Assadsangabi A, Lobo AJ. Diagnosing and managing inflammatory bowel disease. Practitioner 2013;257:13-8, 2.

32. Liu S, Li D, Park R, et al. PET imaging of colorectal and breast cancer by targeting EphB4 receptor with 64Cu-labeled hAb47 and hAb131 antibodies. J Nucl Med 2013:54:1094-100.

33. Heskamp S, van Laarhoven HW, Molkenboer-Kuenen JD, et al. Optimization of IGF-1R SPECT/CT imaging using 111In-labeled $\mathrm{F}\left(\mathrm{ab}^{\prime}\right) 2$ and Fab fragments of the monoclonal antibody R1507. Mol Pharm 2012;9:2314-21.

34. Tang Y, Wang J, Scollard DA, et al. Imaging of HER2/neu-positive BT-474 human breast cancer xenografts in athymic mice using (111)In-trastuzumab (Herceptin) Fab fragments. Nucl Med Biol 2005;32:51-8.

35. Mahmood U. MICoE Task Force Looks to the Future. J Nucl Med 2009:50:15N

36. Cho IH, Han EO, Kim ST. Very different external radiation doses in patients undergoing PET/CT or PET/MRI scans and factors affecting them. Hell J Nucl Med 2014;17:13-8.

37. Zhang $\mathrm{Y}$, Hong $\mathrm{H}$, Orbay $\mathrm{H}$, et al. PET imaging of CD105/endoglin expression with a (6)(1)/(6)(4)Cu-labeled Fab antibody fragment. Eur J Nucl Med Mol Imaging 2013;40:759-67.

38. Vlasak J, Ionescu R. Fragmentation of monoclonal antibodies. MAbs 2011;3:253-63

39. Sihver W, Pietzsch J, Krause M, et al. Radiolabeled Cetuximab Conjugates for EGFR Targeted Cancer Diagnostics and Therapy. Pharmaceuticals (Basel) 2014;7:311-38

40. Tang Y, Scollard D, Chen P, et al. Imaging of HER2/neu expression in BT-474 human breast cancer xenografts in athymic mice using $[(99 \mathrm{~m}) \mathrm{Tc}]-H Y N I C-t r a s t u z u m a b$ (Herceptin) Fab fragments. Nucl Med Commun 2005;26:427-32.

41. Cai W, Chen $\mathrm{K}, \mathrm{He} \mathrm{L}$, et al. Quantitative PET of EGFR expression in xenograft-bearing mice using $64 \mathrm{Cu}$-labeled cetuximab, a chimeric anti-EGFR monoclonal antibody. Eur J Nucl Med Mol Imaging 2007;34:850-8.

42. Kulendran M, Stebbing JF, Marks CG, et al. Predictive and prognostic factors in colorectal cancer: a personalized approach. Cancers (Basel) 2011;3:1622-38.

43. Machin P, Catasus L, Pons C, et al. Microsatellite instability and immunostaining for MSH-2 and MLH-1 in cutaneous and internal tumors from patients with the Muir-Torre syndrome. J Cutan Pathol 2002;29:415-20.

44. Svrcek M, Cosnes J, Tiret E, et al. Expression of epidermal growth factor receptor (EGFR) is frequent in inflammatory bowel disease (IBD)-associated intestinal cancer. Virchows Arch 2007;450:243-4.
45. Rego RL, Foster NR, Smyrk TC, et al. Prognostic effect of activated EGFR expression in human colon carcinomas: comparison with EGFR status. Br J Cancer 2010;102:165-72.

46. Spano JP, Lagorce C, Atlan D, et al. Impact of EGFR expression on colorectal cancer patient prognosis and survival. Ann Oncol 2005;16:102-8.

47. Alexander RJ, Panja A, Kaplan-Liss E, et al. Expression of growth factor receptor-encoded mRNA by colonic epithelial cells is altered in inflammatory bowel disease. Dig Dis Sci 1995;40:485-94. 